\title{
Laryngeal Chemoreflex in Newborn Lambs: Respiratory and Swallowing Response to Salts, Acids, and Sugars
}

\author{
ILYA KOVAR, URBAN SELSTAM, WILLIAM Z. CATTERTON, MILDRED T. STAHLMAN, AND \\ HAKAN W. SUNDELL \\ Department of Pediatrics, The University of Alberta, Edmonton, Alberta, Canada, Department of Pediatrics, \\ Children's Hospital, University of Gothenburg, Gothenburg, Sweden, Department of Pediatrics, Medical College of \\ Georgia, Augusta, Georgia, and Department of Pediatrics, School of Medicine, Vanderbilt University. Nashville, \\ Tennessee, USA
}

\section{Summary}

The laryngeal chemoreflex was tested in a standardized manner in eighteen 1- to 6-day-old lambs. The respiratory and swallowing components of the reflex response to chemical solutions introduced to the larynx were quantified to characterize the function of the receptors and to elucidate what kind of receptors most likely are involved. A relationship between the strength of the stimulus and the respiratory response was found. The response was suppressed with the addition of small amounts of $\mathrm{CaCl}_{2}, \mathrm{NaCl}$, and LiCl. $\mathrm{NaCl}, 0.3-0.6 \mathrm{M}, 0.15 \mathrm{M} \mathrm{NaCl}$ titrated to a $\mathrm{pH}$ of 3-5 with hydrochloric or acetic acid, and 0.25-1.0 M glucose in $0.15 \mathrm{M}$ $\mathrm{NaCl}$ elicited the reflex response.

A quantitative separation was seen in the respiratory response to equimolar concentrations of the salt solutions as well as to the acid solutions in normal saline with equal pH. The response to glucose was significantly reduced after application of potassium gymnemate $(P<0.001)$. A direct relationship between the amount of swallowing and the respiratory response was found $(r=0.83)$. The laryngeal chemoreflex responses to the stimuli used have certain functional characteristics that are similar to taste receptor responses. This would suggest that the taste bud-like structures present in the laryngeal area are likely receptors for mediation of the reflex.

\section{Speculation}

Laryngeal chemoreflex apnea was elicited in newborn lambs with weak salt, acid, and sugar solutions applied to the larynx. The concentrations of these stimuli were similar to those which can be present in regurgitated stomach contents of human infants. If such regurgitated material comes in contact with laryngeal chemoreceptors, apnea, and Sudden Infant Death Syndrome (SIDS) might be elicited.

Laryngeal chemosensitivity has been demonstrated in newborn animals of several species $(2,12,20)$. Different chemical stimuli have been shown to elicit a powerful reflex response involving several organ systems: startle and withdrawal movements, apnea, swallowing, and cardiovascular effects, e.g., bradycardia, hypertension, and blood flow redistribution $(16,21,29)$. Water, acids, sugars, bicarbonate, quinine, and other chemical substances have been tested $(12,28)$ and found to elicit the reflex response in animals. The apnea can be lethal if not interrupted with normal saline solution $(0.15 \mathrm{M} \mathrm{NaCl})$, which in itself does not give a response. It has been concluded that the receptors for the reflex are located in the laryngeal area, because the reflex is abolished if the afferent pathway of the reflex arc through the superior laryngeal nerve is cut $(12,20)$. Structures resembling taste buds present on the dorsal surface of the epiglottis and in the arytenoid area have been implicated as the possible peripheral receptors for the reflex $(12,20)$. However, numerous free nerve endings are present in the laryngeal epithelium (13) that could possibly function as receptors for the reflex (28).

The purpose of the present study was to characterize the function of the receptors by means of the respiratory and swallowing response to various stimuli and to elucidate what kind of receptors might be involved. It is recognized that taste is a subjective sensation and cortical in character and it is not implied that taste perception is involved in the larynx reflex. However, the ability of a chemical stimulus to elicit a receptor response should be characteristic for the interaction between the quality of the stimulus and of the receptor cell. A comparison between the magnitude of the laryngeal chemoreflex responses and the lingual taste responses to the same stimuli might therefore tell us something about which type of receptor is present.

\section{METHOD}

\section{PREPARATION}

Eighteen healthy, normally grown, term lambs of Dorset or Suffolk-Dorset mixed breeds were studied in the prone position. All lambs, except one, were 1 to 6-days-old. A 16-day-old lamb was also studied. It did not show a different response when compared to the younger lambs. It was, therefore, included in the data analysis. Chloralose anesthesia was used as a $1 \%$ solution in saline given iv by intermittent bolus as needed to keep the lambs lightly anesthetized without voluntary movements. The total dose did not exceed $5 \mathrm{mg} / \mathrm{kg}$. Catheters were introduced into the tarsal vein and femoral arteries. The venous catheter was used for administration of anesthesia and a continuous dextrose infusion. The arterial catheters were used for continuous oxygen monitoring (International Biophysics Corporation), blood pressure recording, and intermittent blood gas and $\mathrm{pH}$ analysis. A low double tracheostomy was performed with care to avoid the superior laryngeal and vagal nerves. Spontaneous ventilation of the lungs continued via the downward directed tube (Portex 4-5), that was connected to a Babybird respirator with continuous air flow. This allowed humidification and added oxygen if required. The upward directed tube (Portex 2.5) was placed below the larynx and was used for introduction of test solutions retrograde over the sensitive laryngeal area. The esophagus was left intact.

Respiratory frequency, changes in tidal volume and pattern were monitored using transthoracic impedance signal from tetrapolar electrodes placed on either side of the thorax (Respimeter, Saab-Scania). The swallowing pattern was also recorded by an impedance signal (Parks Electronic Lab) across the laryngeal region or by an electromyogram of the thyrohyoid muscle. The 
electrocardiogram and the integrated heart rate based on $R$ wave triggering were also recorded. All recordings were made with a 6 channel Sanborn 350 physiologic recorder. The preparation of the lamb required $2-3 \mathrm{hr}$, and the subsequent experiment lasted 4-5 hr. The clinical state of the lamb was continually monitored through the experimental period with frequent blood sugar and blood gas analysis, with corrections being made as required. Rectal temperature was kept at $39^{\circ} \mathrm{C}$.

\section{EXPERIMENTAL PROTOCOL}

The reflex response to chemical solutions that are known taste stimuli in man (salt, sweet, and sour) was tested in a standardized manner. The test solutions were freshly made each day. Distilled water was used for the water stimulus and as the solvent for the salt solutions. Solutions were kept warm in a water bath at the lamb's body temperature of $39^{\circ} \mathrm{C}$. Fifteen $\mathrm{ml}$ of the test solution was introduced retrograde to the larynx through the upper tracheostomy tube over a 15 -sec period and then flushed away at $20 \mathrm{sec}$ with normal saline. The lambs were allowed to recover between each test. Respiration, blood pressure, and heart rate were continuously monitored in order to indicate that the animal had returned to the original baseline state before the next test was performed. The arterial $\mathrm{PO}_{2}$ was kept greater than 60 torr. The $\mathrm{PCO}_{2}$ ranged between 30-40 torr. Solutions of various dilutions were tested in both a random and a stepwise fashion with repeated checks of the reference water and normal saline reaction to confirm the continued integrity of the system.

Six lambs were tested with salt solutions (sodium chloride, calcium chloride, and lithium chloride). Sugars and acids, both of which give apnea, were mixed in normal saline instead of water so that the apnea inducing effect of the stimulus would be independent of the solvent. Five lambs were tested with acetic and hydrochloric acid dissolved in normal saline titrated with a Beckman $\mathrm{pH}$ meter to different hydrogen ion concentrations. Eleven lambs were tested with glucose in normal saline. Taste modification with potassium gymnemate, a known taste modifier for sugars was performed in five lambs. Potassium gymnemate $100 \mathrm{mg}$ was dissolved in $85 \mathrm{ml}$ of distilled water and titrated to a $\mathrm{pH}$ of 7 with hydrochloric acid. The solution was flushed over the laryngeal region and cleared with normal saline after $2 \mathrm{~min}$.

\section{SCORING SYSTEMS}

Water and normal saline $(0.15 \mathrm{M} \mathrm{NaCl})$ provide the reference reactions for the reflex. The typical reaction to water stimulation is illustrated in Figure $1 \mathrm{~A}$ and consists of: (1) immediate apnea; (2) rapid swallowing; (3) systolic and diastolic hypertension; and (4) variable heart rate change. In this example, bradycardia is seen, although frequently the anesthetized lamb shows no change in heart rate and occasionally, a tachycardia will be seen. Normal ventilation can be restored by the application of normal saline. The typical normal saline response is no apnea, no heart rate or blood pressure changes, and no swallowing. In Figure IB, an intermediate reaction is illustrated when the stimulus is $0.06 \mathrm{M}$ sodium chloride. The period of apnea is brief and ventilation returns spontaneously despite continued stimulation.

In order to have a basis for comparison between the respiratory reflex responses to the different test stimuli, a scoring system was devised. This provides a way to quantify the severity of any apnea seen, and allows comparison between the responses within the same lamb and between different lambs to the varying stimuli or to the same stimulus at different times in the experimental period. The score (= apnea score) incorporates the change in tidal volume (height of the impedance excursion), changes in respiratory rate, and the length of the apnea during the 15-sec stimulation period as compared with the spontaneous respiratory pattern of the preceding baseline 15-sec period. In effect, it gives a measure of the loss of ventilation during the applied stimulus. A 0 to 10 scale is used.

The apnea score may be calculated by the following equation:

$$
\text { Apnea score }=\frac{\Sigma \mathrm{a}-\Sigma \mathrm{b}}{\Sigma \mathrm{a}} \times 10
$$

where $\Sigma \mathrm{a}=$ sum of the heights of the impedance deflections during baseline time $\Sigma b=$ the sum of the heights of the impedance deflections during stimulation time.

B.
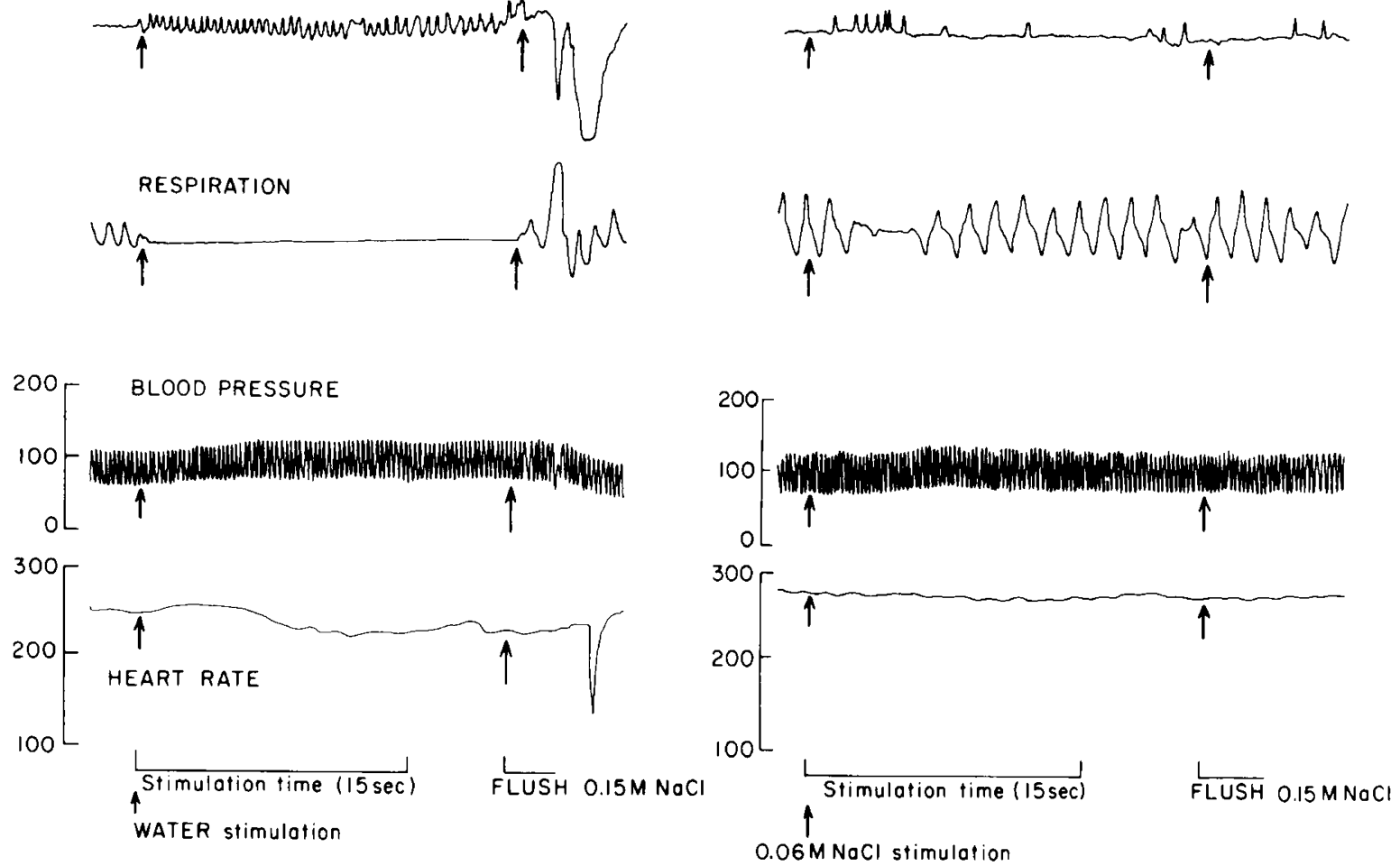

Fig. 1. Recordings from a 4-day-old dorset lamb showing swallowing, respiratory pattern, blood pressure, and heart rate response to laryngeal shemostimulation. Chart speed $5 / \mathrm{mm} / \mathrm{sec}$. $A$ ) Response to water stimulation. $B$ ) Response to $0.06 \mathrm{M}$ sodium chloride. 
A 0 score indicates no change in ventilation as seen with normal saline stimulation. A 10 score indicates total apnea over the 15 -sec stimulation period as seen with water. The apnea score for the respiratory response illustrated in Figure $1 \mathrm{~B}$ is 4 . Spontaneous respiration may resume despite continued stimulation, after the stimulation is discontinued, after a saline flush, or occasionally only after a period of positive pressure ventilation.

Rapid swallowing with water stimulation is a feature of the reflex. With brief periods of apnea, there is less swallowing. A score $(0-4)$ was used to quantify swallowing.

$0=$ no swallowing during the 15 -sec stimulation period

$1=$ occasional, solitary swallowing only

$2=$ more than occasional ( = bursts) swallows throughout less than $50 \%$ of stimulation time.

$3=$ swallowing throughout more than $50 \%$ of the stimulation time

$4=$ swallowing throughout $100 \%$ of the stimulation time

The scoring systems are related to the 15 -sec stimulation period and allow comparison between the swallowing and the respiratory response.

\section{RESULTS}

\section{RESPIRATORY COMPONENT}

Stimulation with salts. Using six lambs, a dose-response relationship was established for weak sodium chloride, calcium chloride, and lithium chloride solutions (Fig. 2). Only a slight change in the respiratory pattern occurred with a concentration of $0.15 \mathrm{M}$. Progressive apnea resulted from more dilute solutions. The results indicate that calcium chloride gives less apnea than sodium chloride that gives less apnea than lithium chloride at the same molar concentrations. The ranking order of the ability of the three ions to induce apnea as evaluated by dose-response curves in the individual lambs was consistent in $4 / 6$ lambs. The response to sodium chloride and lithium chloride was similar, but clearly greater than to calcium chloride in the other two lambs. Stimulation with $0.06 \mathrm{M} \mathrm{NaCl}$ gave a respiratory response with a mean apnea score of 5 . At this concentration, the separation in responses between the three salts is pronounced. Although there is some overlap at low and high concentrations, the curves suggest quantitative separation between the responses to these salts.

Hypertonic sodium chloride solutions with concentrations of 0.3-0.6 M elicited the reflex response with increasing apnea proportional to the sodium chloride concentration (Fig. 3). Stimulation with concentrations of $0.30-0.45 \mathrm{M} \mathrm{NaCl}$ result in a decrease in tidal volume, which does not return before the normal saline flush. The normal saline used to flush away the hypertonic solu-

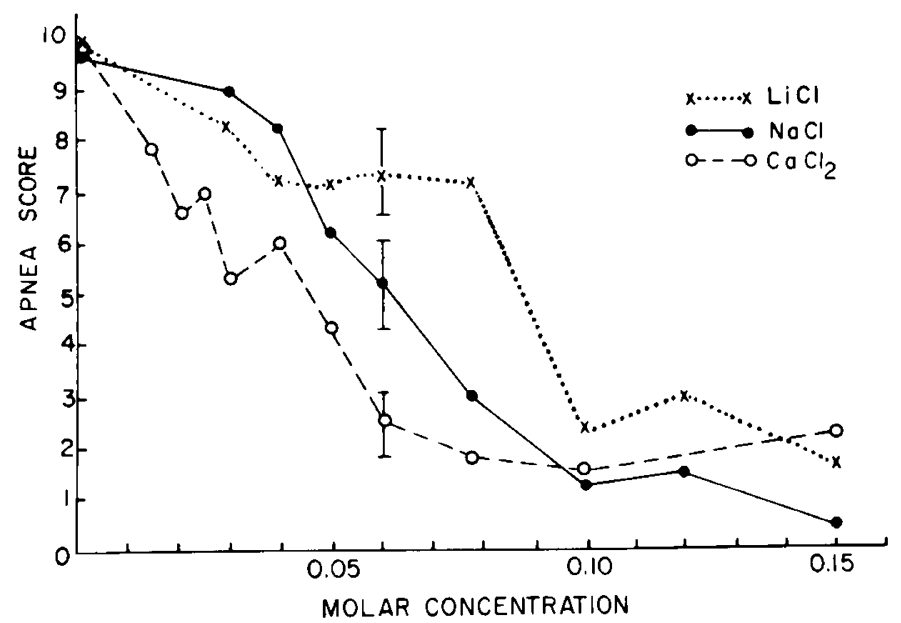

Fig. 2. Respiratory response to laryngeal stimulation, expressed as apnea score, with varying concentrations of $\mathrm{LiCl}, \mathrm{NaCl}$, and $\mathrm{CaCl}_{2}$. Each point represents the mean of six observations in six newborn lambs. I $=$ Mean \pm SEM. tions produces total apnea during the 15 -sec flushing time (Figure 4A). A rapid return to the baseline respiratory pattern is seen thereafter. Stronger solutions with $0.5-0.6 \mathrm{M} \mathrm{NaCl}$ gave a response with progressive decrease of the tidal volume leading to complete apnea, which lasted beyond the stimulation period and was not reversed until after the flush with normal saline (Fig. 4B).

Milk contains low concentrations of sodium chloride in the range of $0.007-0.030 \mathrm{M}$. Milk from sheep, cow, and goat, as well as proprietary formula, were tested in five lambs and all produced marked apnea. The apnea response could be eliminated by raising the sodium concentration of the milk to $0.07 \mathrm{M}$.

Stimulation with acids. Saline titrated to a $\mathrm{pH}$ of 3-5 with acetic and hydrochloric acid was tested in five lambs. The respiratory response is a function of the specific acid and the pH (Fig. 5). A consistently higher apnea score was produced by acetic acid than by hydrochloric acid when both acids were tested at submaximal response levels. (Apnea score less than 10). There is a quantitative separation in the responses to these two acids for $\mathrm{pH} 4$ and 5 ( $P$ $<0.025$ and $P<0.01$, respectively, by paired $t$ test). After using a $\mathrm{pH}$ of 3 or less, the integrity of the system may be altered, with apnea resulting from normal saline or incomplete apnea from a water stimulus.

Stimulation with sugars. Glucose dissolved in normal saline was tested at concentrations of $0.25-1.0 \mathrm{M}$ in 11 lambs (Fig. 6). Progressive apnea is seen with increasing glucose concentrations. A dose-response relationship exists for concentrations $0.25-0.75$ $\mathrm{M}$. Other sweet stimuli such as $0.25-1.0 \mathrm{M}$ sucose, $0.25-1.0 \mathrm{M}$ lactose and $0.05-0.1 \mathrm{M}$ saccharin diluted in normal saline were tested in one lamb and were also found to give apnea. The respiratory response is significantly reduced after application of the taste modifier potassium gymnemate to the laryngeal area $(P$ $<0.001$ by paired $t$ test) (Fig. 7). The response to normal saline alone and to water are unchanged.

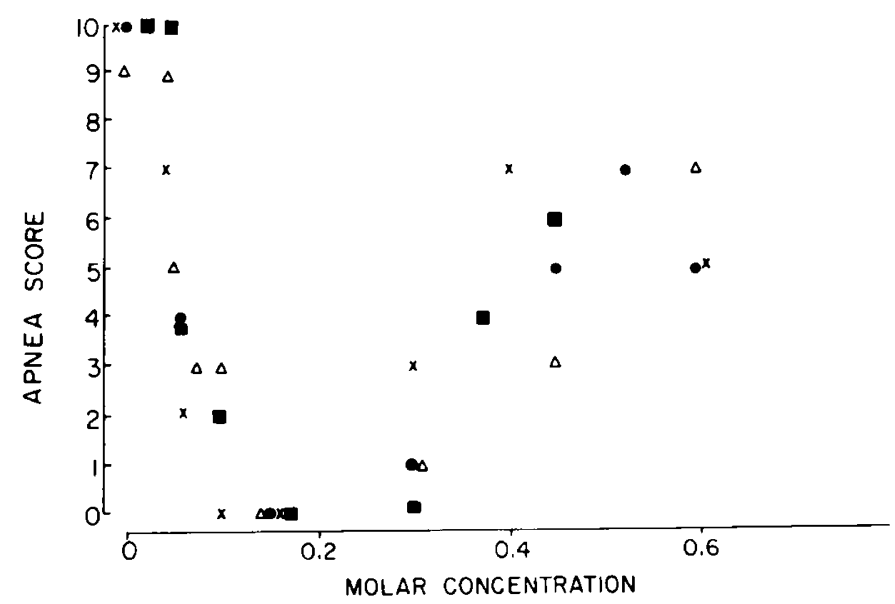

Fig. 3. Respiratory response to laryngeal chemostimulation with water and 0.03-0.60 M sodium chloride solutions in four newborn lambs. Each symbol represents one stimulation on a single lamb.
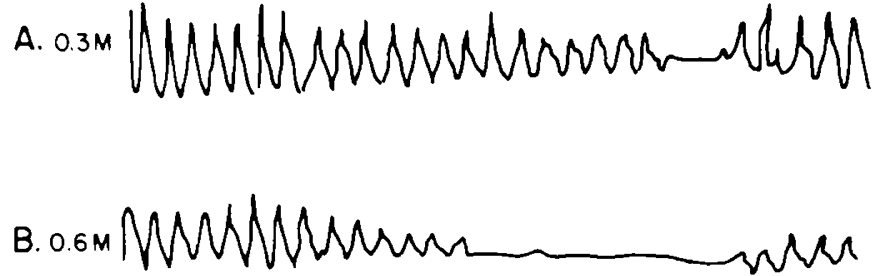

\section{SECONDS HYPERTONIC NoCt}

Fig. 4. Respiratory impedance tracings from a 5-day-old dorset lamb showing respiratory changes during laryngeal chemostimulation with hypertonic $(0.3$ and $0.6 \mathrm{M})$ and normal $(0.15 \mathrm{M})$ sodium chloride solutions. The sequence of stimuli is indicated below trace B. Chart speed $5 \mathrm{~mm} / \mathrm{sec}$ 


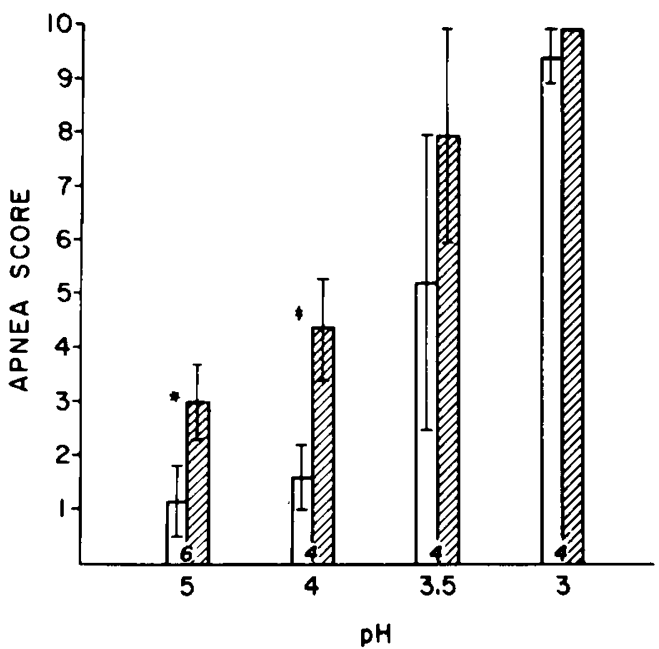

Fig. 5. Respiratory response to laryngeal chemostimulation with acetic and hydrochloride acid in $0.15 \mathrm{M} \mathrm{NaCl}, \mathrm{pH}$ of the stimulating solutions is indicated on the abscissa. Five lambs were studied. $\square$ Acetic acid - $\square$ Hydrochloric acid $\amalg$ Mean \pm SEM. The integer indicates the number of observations. * Apnea scores significantly different, $P<0.01$ by paired $t$ test. $\stackrel{\perp}{\perp}$ Apnea scores significantly different, $P<0.025$ by paired $t$ test.

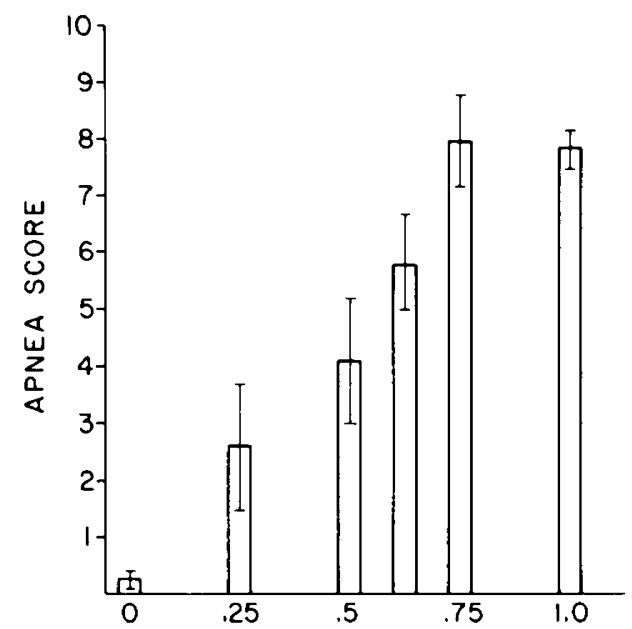

MOLAR CONCENTRATION OF GLUCOSE IN $0.15 \mathrm{M} \mathrm{NaCl}$

Fig. 6. Respiratory response to laryngeal chemostimulation with glucose in $0.15 \mathrm{M} \mathrm{NaCl}$. Eleven lambs were studied. Apnea score plotted as Mean \pm SEM.

\section{SWALLOWING}

Rapid swallowing is a part of the response to stimulation of the laryngeal chemoreflex. A comparison was made between the swallowing and the respiratory response to 194 various stimuli in six lambs. The amount of swallowing was graded with the swallowing score and the respiratory response with the apnea score. A direct relationship between the amount of swallowing activity and the respiratory response was found, correlation coefficient $=0.83$. All tested solutions that elicited a respiratory response also produced a swallowing response. There was no difference in this relationship for the solutions included in the study.

\section{DISCUSSION}

This study was aimed at functional characterization of the chemoreceptors in the anesthetized newborn lamb. The respiratory component of the reflex was used as a measure of the response. The respiratory responses to standardized chemical stimuli applied to the laryngeal area were evaluated with a scoring system, which expresses the amount of ventilation lost during the stimulation

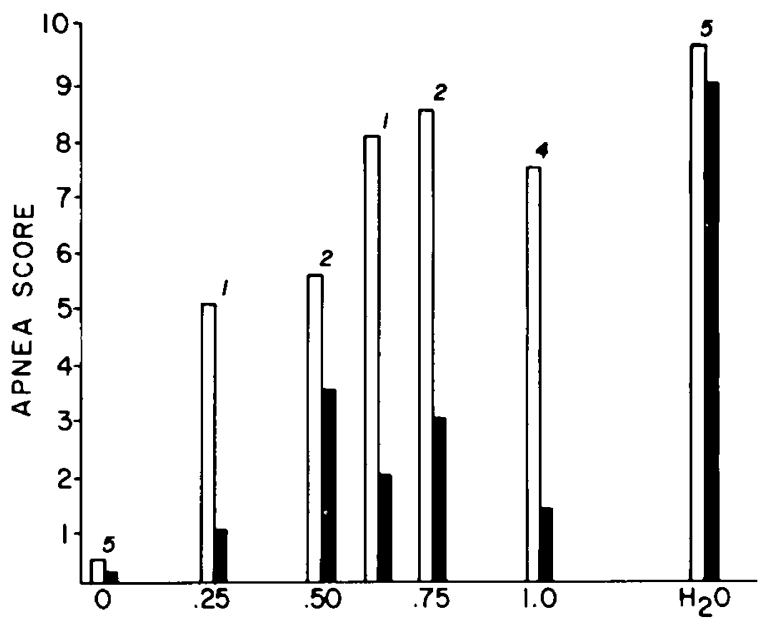

MOLAR CONCENTRATION OF GLUCOSE IN $0.15 \mathrm{M} \mathrm{NoCI}$

Fig. 7. Effect of potassium gymnemate (KG) on the respiratory response to glucose in $0.15 \mathrm{M} \mathrm{NaCl}$ and water stimulation in five newborn lambs. Bars express mean apnea scores: $\square$ before $K G$ and $\square$ after KG. Integer indicates number of observations. Apnea scores for glucose in saline before and after KG were significantly different. $P<0.001$ by paired $t$ test.

time as related to the baseline period. Although the interpretation of the transthoracic impedance is somewhat imprecise, it offers a useful estimate of the response, so that comparisons can be drawn between various tests in different animals.

Corpuscular sensory receptors, anatomically similar to lingual taste buds, have been identified in the laryngeal region, predominantly at the entrance to the lower airway on the dorsal surface of the epiglottis, and on the arytenoid area of many species including man $(2,10,19)$. A rich variety of other sensory endings have also been found on the laryngeal surface of the epiglottis (13). The actual receptors for the laryngeal chemoreflex have not been identified with certainty. Electrophysiologic studies by Storey and Johnson (28) have showed that discharge characteristics of the laryngeal sensory units reactive to water are dissimilar to taste units. They, therefore, considered it unlikely that the taste buds are the receptors. Harding et al. (17) have recently shown in newborn lambs, kittens, and monkeys that water-sensitive units can be located in regions of the upper airway which are devoid of taste buds, and suggest that there may be more than one type of laryngeal chemoreceptors.

It was hypothesized that laryngeal taste buds are receptors for the chemoreflex and, if so, that they might share some functional characteristics with the taste receptors on the tongue. A solution with very sour taste should, therefore, be expected to give a higher apnea score than a solution tasting less sour. Contrariwise, a salty stimulus should produce a low apnea score if it has a low taste threshold. Our findings with salts and acids are consistent with this hypothesis.

The results have shown that the reflex does not follow the all or none principle with a distinct stimulus threshold, but rather there is a relationship between the strength of the stimulus and the respiratory response. This was found for all substances tested, e.g., salts, acids, and sugars. There was also a discrimination for salts and acids which gave quantitatively different respiratory responses for various stimuli of the same molar concentration. The degree of salty taste for chloride salts has been found in man to be $\mathrm{Ca}>\mathrm{Na}>\mathrm{Li}(26)$. This order for the salts closely resembles the series found in rejection thresholds in animals (14). Beidler $e t$ al. (8) showed, however, that the relative magnitude of electrical responses of the chorda tympani nerve to chemical stimulation with different salts to the tongue varied, and that the order of effectiveness among the tested salts (e.g., $\mathrm{LiCl}, \mathrm{NaCl}$, and $\mathrm{CaCl}_{2}$ ) was not consistent among various animal species or for two nerves in the same species. Electrophysiologic or psychophysical tests reported on sheep are very limited $(9,15)$. Using electrophysiologic 
recordings from the chorda tympani nerve of fetal and newborn lambs, Bradley and Mistretta (11) have, however, found that lingual stimulation with $0.5 \mathrm{M}$ lithium chloride produced more effect than $0.5 \mathrm{M}$ sodium chloride.

Apnea produced by various kinds of milk appeared to be mainly related to the sodium chloride concentration and was eliminated by raising the $\mathrm{NaCl}$ concentration to $0.07 \mathrm{M}$. This concentration did not produce apnea when the lambs were tested with the series of $\mathrm{NaCl}$ dilutions.

The complete apnea response to normal saline after hyperosmolar sodium chloride solutions could be explained by considering adaptation of the receptor to the high sodium chloride concentration (26) and the subsequent recognition of normal saline as more dilute, giving a water-like response. Such adaptation is known to occur for the lingual taste receptors $(1,25,31,32)$ and, indeed, the response to water in cats is contingent on the preceding adapting stimulus (5). The laryngeal chemoreceptors, which do not respond to isotonic saline but respond progressively to hypotonic solutions and maximally to pure water, might function like the lingual sensory units in the cat described by Bartoshuk et al. (5) that respond to water - after $\mathrm{NaCl}$, but not to $\mathrm{NaCl}$. Akaike and Sato (1) have recently demonstrated with recordings of membrane potential changes in single taste cells on the frog tongue, that the same taste cell can respond to deionized water and $\mathrm{NaCl}$ in concentrations above adaptation concentrations as well as to sucrose. Because the laryngeal receptors also responded with apnea to these solutions (Figs. 2, 3, and 6) one might postulate that they function like the taste cells in the frog described by Akaike and Sato.

Sourness is mainly related to the hydrogen ion concentration but also depends on the anion, as different acid solutions with the same $\mathrm{pH}$ give different intensities of sourness. Acetic acid was found by Richards (27) as well as by Beidler (6) and Kurihara (22) to be more "sour" than hydrochloric acids in human taste studies. The difference in stimulating ability between these acids corresponds to that obtained in rejection studies on rabbits (14) as well as that found in electrophysiologic studies in rats (6). Beidler explained the difference in sourness as a local effect of the stimulating ions on the taste receptor membrane (7).

Further support for the theory that taste buds function as laryngeal chemoreceptors is obtained from the sugar study. The lambs reacted with increasing apnea to progressively stronger glucose concentrations in normal saline (Fig. 6). Lingual taste response to sugars including glucose have been demonstrated in sheep by Bell and Kitchell (9) and by Goatcher and Church (15). The leaves of the Indian plant Gymnema Sylvestre is known to suppress taste sensitivity to sweet substances. The active form is potassium gymnemate $(30)$. The mode of action is not known, but it has been thought to bind to the sweet receptor site on the taste membrane (23). Taste modification with potassium gymnemate markedly reduced the response to glucose but did not alter the response to saline and water, as one would expect from the taste studies with potassium gymnemate applications on the human tongue $(4,30)$.

Although some similarities between the respiratory response of the laryngeal chemoreflex to laryngeal taste stimuli and psychophysical and electrophysiologic responses to lingual taste stimuli have been shown, caution must be taken in interpreting the findings. Species differences do exist and there are limited data available on taste physiology in sheep.

The response to laryngeal chemostimulation has several components. The respiraory response has principally been presented in this study. This response has been described as graded and proportional to the strength of the stimulus. This direct relationship between the magnitude of the stimulus and the response also exists for the other components of the reflex such as swallowing.

The clinical implications of these findings and their relationship to Sudden Infant Death Syndrome and apnea of prematurity are only speculative. Respiratory arrest has recently been described in 10 children less than 6 months old, which appeared to be due to gastroesophageal reflux (24). The observation in the newborn lambs that the reflex can be elicited by acid solutions with a $\mathrm{pH}$ of 3-4 is of special interest. This degree of acidity is in the range of that found in the stomach contents of newborn term or preterm infants $(3,18,29)$. It is possible that, in the young infant, small regurgitations of acid or sweet stomach contents, or those hypotonic for salt, may stimulate the reflex and lead to apnea and hypoxia.

\section{CONCLUSION}

The laryngeal chemoreflex was tested in a standardized manner in 18 newborn lambs. Salt, acid, and sugar solutions were used to evaluate the larynx reflex. The respiratory and swallowing components of the reflex response were quantified using scoring systems.

A dose response relationship was established for all stimulating substances. Weak salt solutions, $\left(<0.15 \mathrm{M} \mathrm{NaCl}, \mathrm{LiCl}\right.$, and $\left.\mathrm{CaCl}_{2}\right)$ inhibited the reflex. The reflex response was elicited by $\mathrm{NaCl}>$ $0.3 \mathrm{M}$ and $0.15 \mathrm{M} \mathrm{NaCl}$ with added hydrochloric or acetic acid titrated to a pH of 3-5 and $0.25-1.0 \mathrm{M}$ glucose in $0.15 \mathrm{M} \mathrm{NaCl}$. A quantitative separation in the respiratory response to equimolar concentrations of the salt solutions, as well as the acid solutions in normal saline at equal $\mathrm{pH}$ was seen. The response to glucose was significantly decreased after application of potassium gymnemate. The respiratory and swallowing components of the reflex response were correlated $(r=0.83)$.

The laryngeal chemoreflex responses to the stimuli used have certain functional characteristics which are similar to taste receptor responses. This would suggest that the taste bud-like structures present in the laryngeal area are likely receptors for mediation of the reflex.

\section{REFERENCES AND NOTES}

I. Akaike. N., and Sato, M.: Water response in frog taste cells. Comp. Biochem Physiol., 54A: 149 (1976).

2. Andrew, B. L., and Oliver, J.: The epiglottal taste buds of the rat. J. Physiol. 114: 48P (1951).

3. Avery, G. B., Randolph, J. G., and Weaver, T.: Gastric acidity in the first day of life. Pediatrics, 37: 1005 (1966).

4. Bartoshuk, L. M., Dateo, G. P., Vandenbelt, D. J.. Buttrick. R. L., and Long, L. Effects of gymnema sylvestre and synsepalum dulcificum on taste in man. In Pfaffmann, C.: Olfaction and Taste III p. 436 (New York, Rockefeller University Press, 1969).

5. Bartoshuk, L. M.. Harned, M. A., and Parks, L. H.: Taste of water in the cat effects on sucrose preference. Science. 171: 699 (1971).

6. Beidler. L. M.: Anion influences on taste receptor response. In: Hayashi: Olfaction and Taste II. p. 509 (London, Pergamon Press, 1967).

7. Beidler, L. M.: Taste receptor stimulation with salts and acids. In: Beidler, L. M. Handbook of sensory Physiology, Vol. IV. Chemical Senses, Part 2. p. 200 (Berlin, Heidelberg, New York. Springer Verlag. 1971).

8. Beidler, L. M., Fishman, I. Y.. and Hardiman, C. W.: Species differences in taste responses. Amer. J. Physiol., 181: 235 (1955)

9. Bell, F. R., and Kitchell, R. L.: Taste reception in the goat, sheep, and calf. J. Physiol., 183: 145 (1966).

10. Bradley, R. M., and Cheal. M. L.: Morphological and quantitative study of developing epiglottal taste buds in sheep. Neurosci. Abstracts. 2: 152 (1976).

11. Bradley, R. M., and Mistretta, C. M.: The gustatory sense in foetal sheep during the last third of gestation. J. Physiol., 231: 271 (1973).

12. Downing. S. E., Lee, J. C.: Laryngeal chemosensitivity: A possible mechanism for Sudden Infant Death. Pediatrics. 55: 640 (1975).

13. Feindel, W.: The neural pattern of the epiglottis. J. Comp. Neurol, 105: 269 (1956).

14. Frings, H.: A contribution to the comparative physiology of contact chemoreception. J. Comp. Physiol. Psychol., 41: 25 (1948).

15. Goatcher, W. D., and Church, D. C.: Taste responses in ruminants. 1. Reactions of sheep to sugars, saccharin, ethanol, and salts. J. Animal Sci.. 30: 777 (1970).

16. Harding, R., Johnson, P., Johnston. B. E., McClelland, M. E., and Wilkinson, A. $R$.: Cardiovascular changes in newborn lambs during apnea induced by stimulation of the laryngeal receptor with water. J. Physiol.. 256: 35P (1975).

17. Harding, R., Johnson, P., and McClelland. M. E.: Liquid-sensitive laryngeal receptors in the developing sheep. cat, and monkey. J. Physiol.. 277: 409 (1978).

18. Harries, J. T., and Fraser, A. J.: The acidity of the gastric contents of premature babies during the first fourteen days of life. Biol. Neonate, 12: 186 (1968).

19. Henkin, R. 1., Graziadei, P. P. G., and Bradley. D. F.: The molecular basis of taste and its disorders. Ann. Int. Med.. 71: 791 (1969).

20. Johnson, P., Dawes, G. S., Robinson, J. S.: Maintenance of breathing in newborn lambs. Arch. Dis. Child, 47: 151 (1972).

21. Johnson, P.. Salisbury, D. M., and Storey, A. T.: Apnea induced by stimulation of sensory receptors in the larynx. In: Bosma and Showacre: Development of 
Upper Respiratory Anatomy and Function. p. 160. DHEW Publication (NIH) $75-941$.

22. Kurihara. K., and Beidler, L. M.: Mechanism of the action of taste-modifying protein. Nature. 222: 1176 (1969).

23. Kurihara. K.: Taste modifiers. In: Beidler. L. M.: Handbook of Sensory Physiology, Vol. IV, Chemical Senses, Part 2 p. 363 (Berlin, Heidelberg. New York. Springer Verlag. 1971).

24. Leape, L. L., Holder, T. M., Franklin, J. D., Armoury, R. A., and Ashcraft, K. W.: Respiratory arrest in infants secondary to gastroesophageal reflux. Pediatrics, 60: 924 (1977).

25. McBurney, D. H., and Pfaffmann, C.: Gustatory adaptation to saliva and sodium chloride. J. Exp. Psychol., 65:523 (1963).

26. Pfaffmann. C.. Bartoshuk. L. M., and McBurney, D. H.: Taste Psychophysics. In: Beidler, L. M.: Handbook of Sensory Physiology, Vol. IV. Chemical Senses, Part 2. p. 75 (Berlin. Heidelberg. New York. Springer Verlag. 1971).

27. Richards, T.: The relation of the taste of acids to their degree of dissociation. Amer. Chem. J.. 20: 121 (1898).

28. Storey. A. T., and Johnson. P.: Laryngeal water receptors initiating apnea in the lamb. Exp. Neurology. 47: 42 (1975).

29. Sundell, H.: (Unpublished data).

30. Warren, R. M., and Pfaffmann, C.: Suppression of sweet sensitivity by potassium

Copyright (C) 1979 International Pediatric Research Foundation, Inc. $0031-3998 / 79 / 1310-1144 \$ 02.00 / 0$ gymnemate. J. Appl. Physiol., 14: 40 (1959).

31. Yamashita, S.: Stimulating effectiveness of cations and anions on chemoreceptors in the frog tongue. Jap. J. Physiol., 13: 54 (1963).

32. Zotterman, $Y$. The recording of the electrical response from human taste nerves. In: Beidler, L. M.: Handbook of Sensory Physiology Vol. IV, Part 2. p. 102 (Berlin. Heidelberg. New York. Springer Verlag, 1970).

33. The authors thank Patricia Minton, R. N., David Oliver, and Rao Gaddipati, Research Assistants, for their efficient technical help and Dr. James W. Ward for his advice and discussion.

34. Dr. Catterton is recipient of American Lung Association Training Fellowship.

35. This research was supported by grants from the National Institute of Child Health and Human Development (no. HD 10454-02), and the National Heart. Lung, and Blood Institute (no. HL 14214) and was performed at the Department of Pediatrics, Vanderbilt University School of Medicine, Nashville. Tennessee 37232 (USA).

36. Requests for reprints should be addressed to: Hakan W. Sundell, M. D.. Department of Pediatrics, School of Medicine. Vanderbilt University. Nashville. Tennessee 37232 (USA).

37. Received for publication June 13, 1978

38. Accepted for publication October 24, 1978 